\title{
CCSA Algorithm Compensator Designing in a Solar wind Hybrid Energy System
}

\author{
Asanna kumar Badge \\ M. Tech scholar \\ NRI Institute of Research \& Technology, Bhopal \\ India \\ asanna11@yahoo.com
}

\author{
Mrs. Madhu Upadhyay \\ Head of Department \\ NRI Institute of Research \& Technology, Bhopal \\ India \\ madyant44@gmail.com
}

\begin{abstract}
In recent years, there has been a growing interest in moving away from large centralized electricity production towards distributed energy resources. In this paper are designing of a Hybrid solar/wind system as well as integrating it with the grid system in MATLAB /SIMULINK environment. And Designing of a compensating device and compare it with the basic STATCOM compensator for active power output enhancement in the system. The compensating device control has to be designed with a linear crow optimizing algorithm to obtain a smooth voltage and current waveform. Reduction in the distortion level of the voltage output at the grid system is to be done by using the proposed optimizer. The description concludes that the hybrid system is made efficient for driving the loads having enhanced active power output at its terminal. The voltage available has been made less distorted and the THD level in current output has also came down.
\end{abstract}

Keywords: STATCOM, THD, hybrid system, DG.

\section{INTRODUCTION}

In recent years, there has been a growing interest in moving away from large centralized electricity production towards distributed energy resources. Solar energy production offers numerous advantages for use as a distributed energy source, particularly as a peak energy source. Energy suppliers are currently facing the great challenge of connecting distributed generators (DG) based on renewable energy, while ensuring stability, voltage regulation and energy quality. At night, energy loads are generally much lower than during the day, while wind farms (WF) produce more electricity due to the increase in wind speed.

With the present growth rate of energy consumption the world's energy consumption is doubling every 10 years, which will lead to the depletion of the fossil fuel supply in a few hundred years. This means that other forms of energy will have to be used in the near future. There has recently been growing interest in expanding electricity generation capacity through the use of distributed electricity generation (DEG). DEG consists of placing small production plants (up to ten megawatts) in municipalities and industrial structures at the distribution level. These plants include natural gas micro turbines, fuel cells, wind and solar energy sources. DEG offers many advantages to production companies and customers. The production company will benefit from the fact that it will not have to invest large amounts of capital in a production facility that does not generate a return on investment for several years. Another advantage for the service company is the reduction of the load on the transmission and distribution network (T\&D). By bringing the energy source closer to the end user, the losses in the T\&D lines are reduced. All the advantages mentioned above can be transferred to the end user in the form of lower additional costs. Another advantage for the user would be better energy quality and reliability.

\section{LiterATURE REVIEW}

Emad Jamil et al. [1] this article presents the development of the energy quality for an efficient transfer of energy during a hybrid solar-photovoltaic-wind system integrated within the network. The hybrid system may be a renewable energy park supported a photovoltaic energy generation system and a wind energy conversion system. The system has frequent disturbances in $\mathrm{AC}$ loads and within the output power of renewable operations. This results in a shift in reactive power and poses problems of voltage instability and energy quality. This deviation are often adjusted using an adjustable reactive energy source, e.g. H. A static synchronous compensator to be eliminated. Three case scenarios of hybrid systems, i. H. 
Hybrid systems in standalone (I), integrated network (II) and integrated network (III) modes with STATCOM are tested to compare their dynamic and transient performance. The results show that scenario III best met the dynamic compensation requirement altogether cases.

Tariq Kamal et al. [2] this work allows dynamic operation and monitoring of a hybrid renewable energy system, which supplies electricity both in simple operation and on the grid. It contains photovoltaic because the main source, which is controlled via fuzzy, and a proton exchange membrane cell (PEMFC) as a secondary source, which is controlled via a proportional integral differential controller (PID). The high intermittence of photovoltaic is addressed by integrating the super capacitor and therefore the battery pack within the proposed architecture. the overall strategy of the proposed system is administered using dynamic power switches of the converters.

Gilberto Gonzalez-A et al. [3] The modeling within the connection graph of a Sky stream turbine, which consists of blades, a synchronous permanent magnet generator (PMSG), a three-phase rectifier, a step-up converter, and an inverter, which is assessed as little system. The connection graphs allow the modeling of systems composed of various energy fields. The Sky Stream turbine may be a good case study to demonstrate that the link graph model is represented during a unified approach. The electricity production system supported this turbine is three-phase. The utilization of multiband graphics is proposed to model the PMSG, the three-phase rectifier and therefore the inverter. However, the blades and therefore the boost converter are modeled by single link graphics. The mathematical representation of a neighborhood of the sheet and of the PMSG is obtained.

Sujit Kumar Bhuyan et al. [4] the proposed hybrid energy system (HES) consists of a photovoltaic system (PV), the electrolyze, the tank and therefore the solid oxide cell (SOFC). HES is employed to power the $3 \varnothing$ load and therefore the $1 \varnothing$ load, which is synchronized with the network via the voltage source converter (VSC). With this technology, if the photovoltaic energy is insufficient to satisfy the load demand, SOFC electricity is used to satisfy the requested demand. A cell regulator is proposed that uses a PID regulator to manage the quantity of hydrogen (H2) through the valve and is used as a fuel for SOFC. During this article, $\mathrm{H} 2$ is generated by an electrolyze that uses additional photovoltaic energy and water as input.

\section{OBJECTIVE}

The work has been focused on obtaining following key objectives:

- Designing of a Hybrid solar/wind system as well as integrating it with the grid system in MATLAB /SIMULINK environment.

- Designing of a compensating device and compare it with the basic STATCOM compensator for active power output enhancement in the system.

- The compensating device control has to be designed with a linear crow optimizing algorithm to obtain a smooth voltage and current waveform.

- Reduction in the distortion level of the voltage output at the grid system is to be done by using the proposed optimizer.

\section{Methodology}

The large-scale wind/solar hybrid system is connected to grid via a booster station. The system consists of wind power system and photovoltaic system. In order to improve the transient voltage stability of the large-scale wind/solar hybrid system, reactive power compensation device STATCOM is connected to grid. The compensator is being proposed for further enhancement in the output parameters like THD in voltage, THD in current and active power output.

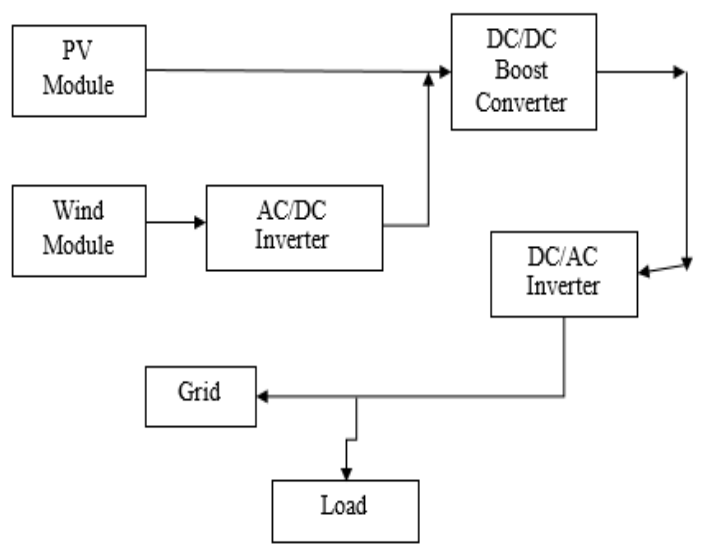

Fig.1. Hybrid energy system topology

As shown in Fig. 1, the wind power generation system consists of DFIG wind turbine and $\mathrm{AC} / \mathrm{DC}$ inverter.

\section{A. PV Module modelling}

PV cells have single operating point where the values of the current (I) and voltage (V) of the cell result in a maximum power output. These values correspond to a 
particular resistance, which is equal to V/I. A simple equivalent circuit of PV cell is shown in Fig. 2.

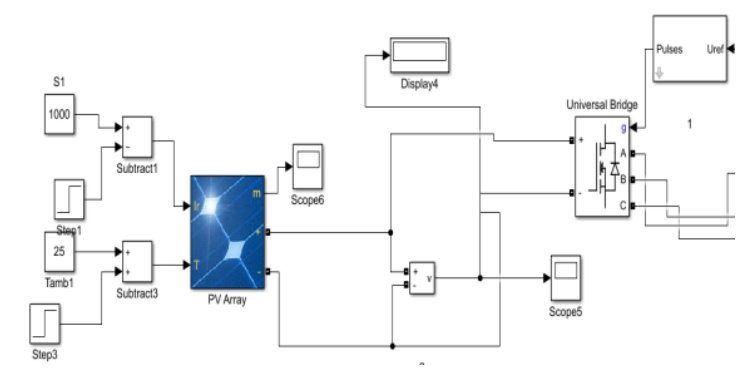

Fig. 2. Modeled solar system

A cell series resistance ( Rs ) is connected in series with parallel combination of cell photocurrent ( $\mathrm{I}_{\mathrm{ph}}$ ), exponential diode ( D ), and shunt resistance $\left(\mathrm{R}_{\text {sh }}\right)$, I pv and Vpv are the cells current and voltage respectively. It can be expressed as

$$
\begin{gathered}
I_{p v}=I_{p h}-I_{s}\left(e^{q\left(V_{p v}+I_{p v} * R_{s}\right) / n K T}-1\right)-\left(V_{p v}+I_{p v}\right. \\
\left.* R_{s}\right) / R_{s h}
\end{gathered}
$$

Where:

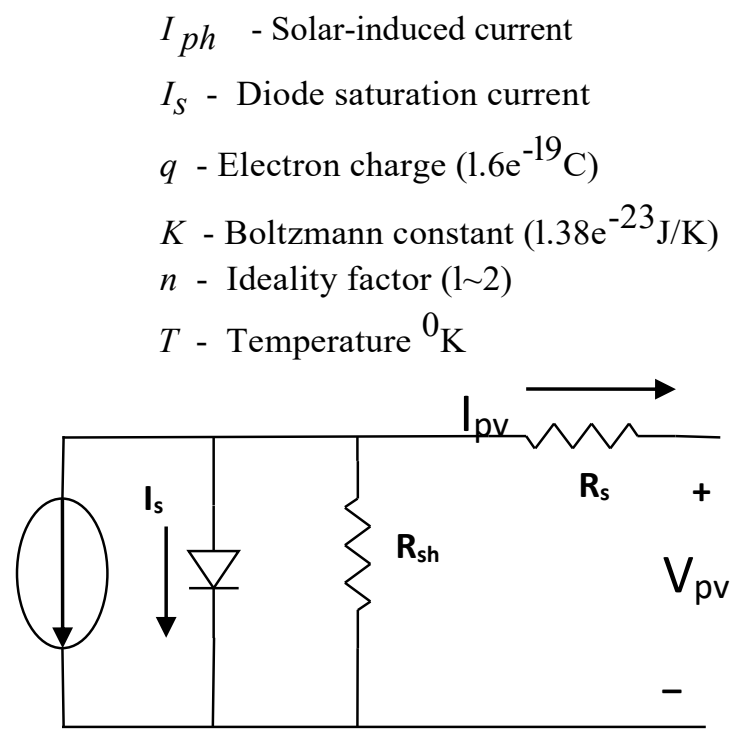

Fig. 3. Equivalent circuit of solar pv cell

The solar induced current of the solar PV cell depends on the solar irradiation level and the working temperature can be expressed as:

$$
I_{p h}=I_{s c}-k_{i}\left(T_{c}-T_{r}\right) * \frac{I_{r}}{1000}
$$

Where:
$I_{S C}$ Short-circuit current of cell at STC

$K_{i}$ Cell short-circuit current/temperature coefficient $(\mathrm{A} / \mathrm{K})$

$I_{r}$ Irradiance in $\mathrm{w} / \mathrm{m}$

$T_{c}, T_{r}$ Cell working and reference temperature at STC

A PV cell has an exponential relationship between current and voltage and the maximum power point (MPP) occur at the knee of the curve as shown in the Fig 4.

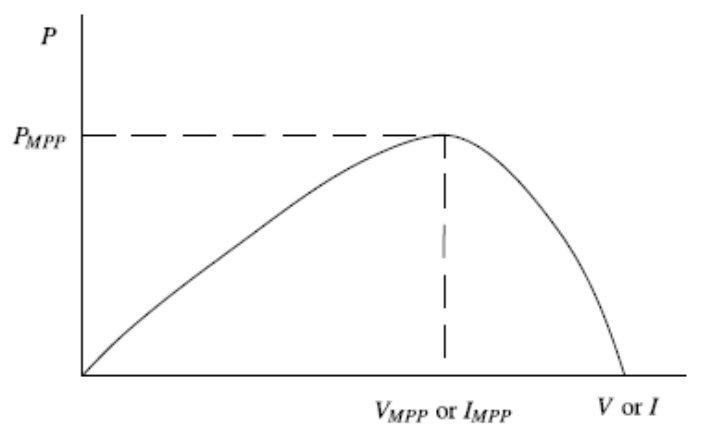

Fig. 4. Characteristic PV array power curve

The $\mathrm{P} \& \mathrm{O}$ algorithm will track the maximum power to supply the DCMGs system. The assumptions for model derivation are that the ideal current source can be presented as the PVs behavior. In addition, all power converters are operated under the continuous conduction mode (CCM) and the harmonics are also ignored.

\begin{tabular}{|l|l|}
\multicolumn{1}{|c|}{ Table 1. PV module Parameters } \\
\hline Maximum Power & 213.5 Watts \\
\hline Number of parallel strings & 40 \\
\hline Number series modules & 10 \\
\hline Open circuit voltage & 36.3 Volts \\
\hline Shot circuit current & 7.84 Ampere \\
\hline
\end{tabular}

\section{B. Wind energy system modeling}

The model of a wind turbine with PMSG wind turbines is unable to fully record wind energy. The components of the wind turbine were modeled using the following equations [8-10].

Output aerodynamic power of the wind-turbine is expressed as:

$$
P_{\text {Turbine }}=\frac{1}{2} \rho A C_{p}(\lambda, \beta) v^{3}
$$

Where, $\rho$ is the air density (typically $1.225 \mathrm{~kg} / \mathrm{m} 3$ ), $A$ is the area swept by the rotor blades (in $\mathrm{m} 2$ ), $C P$ is the 
coefficient of power conversion and $v$ is the wind speed (in $\mathrm{m} / \mathrm{s}$ ).

The tip-speed ratio is defined as:

$$
\lambda=\frac{\omega_{m} R}{v}
$$

Where $\omega_{m}$ and $R$ are the rotor angular velocity (in $\mathrm{rad} / \mathrm{sec}$ ) and rotor radium (in $\mathrm{m}$ ), respectively.

The wind turbine mechanical torque output $m T$ given as:

$$
T_{m}=\frac{1}{2} \rho A C_{p}(\lambda, \beta) v^{3} \frac{1}{\omega_{m}}
$$

The power coefficient is a nonlinear function of the tip speed ratio $\lambda$ and the blade pitch angle $\beta$ (in degrees). Then Power output is given by

$$
P_{\text {Turbine }}=\frac{1}{2} \rho A C_{p_{\text {max }}} v^{3}
$$

A generic equation is used to model the power coefficient $C_{P}$ based on the modeling turbine characteristics described in [2], [7-9] and [11] as:

$$
C_{p}=\frac{1}{2}\left(\frac{116}{\lambda_{i}}-0.4 \beta-5\right) e^{-\left(\frac{21}{\lambda_{i}}\right)}
$$

For each wind speed, there exists a specific point in the wind generator power characteristic, MPPT, where the output power is maximized. Thus, the control of the WECS load results in a variable-speed operation of the turbine rotor, so the maximum power is extracted continuously from the wind.

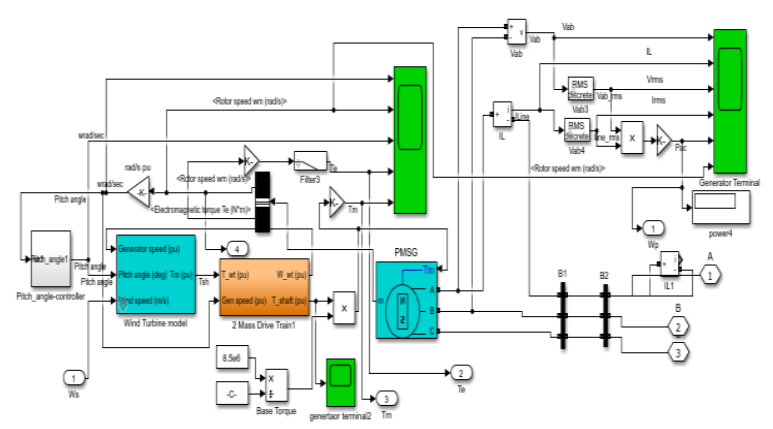

Fig. 5. Modeled Wind system

This mechanism uses the variable torque output $\mathrm{w}_{\mathrm{m}}$ and tries to optimize the output current and voltage waveform to its maximum value.

\begin{tabular}{|l|l|}
\hline Table 2 wind energy system Parameters \\
\hline Maximum Power & 213.5 Watts \\
\hline Number of parallel strings & 40 \\
\hline Number series modules & 10 \\
\hline Open circuit voltage & 36.3 Volts \\
\hline Shot circuit current & 7.84 Ampere \\
\hline
\end{tabular}

\section{CCSA algorithm}

Conventional research methods have long been used to solve design problems. Although these methods show promising results for many real-world problems, they can fail with more complex design problems. With real design problems, the number of decision variables can be very high and their impact on the objective function can be very complicated. The target function can have many local optima, while the designer is interested in the global optimum. Such problems cannot be solved with conventional methods which only find local optima. In these cases, effective optimization methods are needed.

Crows (family of crows or crows) are considered the most intelligent birds. They contain the largest brain in relation to their size. Based on a brain / body ratio, your brain is slightly smaller than that of a human brain. There is much evidence of the crows' ability. They have shown confidence in the mirror test and are able to create tools. Crows can remember faces and warn themselves when a hostile person approaches. They can also use tools, communicate intelligently and remember their heirloom food hiding until a few months later.

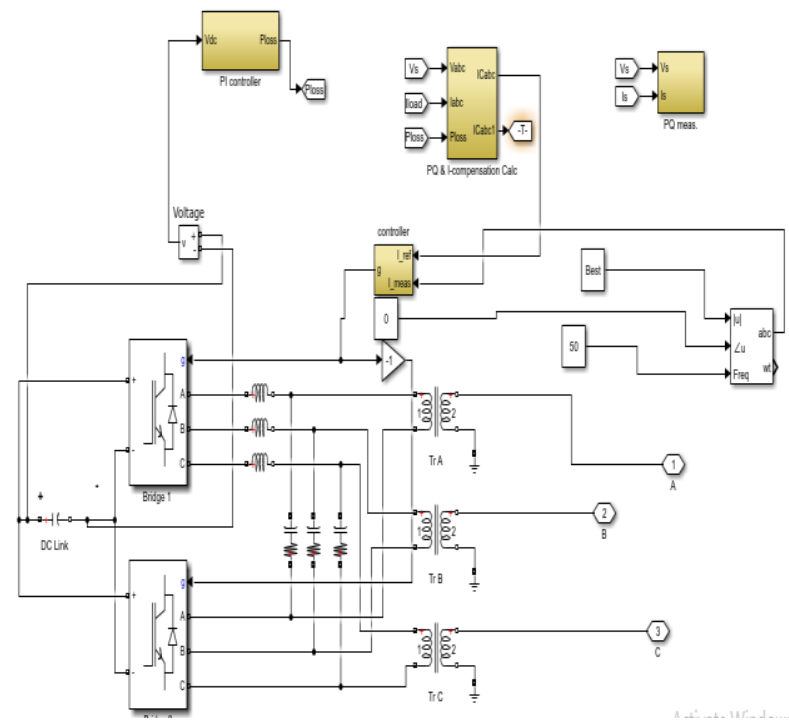

Fig. 6. Compensator with proposed constrained crow search algorithm

\section{RESUlts}

In this world of depleting energy resources the use of renewable based source of energy is highly required to meet the demands of future. The use of solar and wind energy resources for the generation of electricity is the best choice for combating the use of the exhaustible resources. The best part is that it is also a clean source for 
generating electricity. This field is henceforth chosen for our work on these resources.

The work focuses on analysis of a hybrid solar /wind energy system by implementing it in MATLAB/SIMULINK software. The system is made to get integrated with the grid system also in order to enhance its efficiency. The chapter here discusses the solar/wind energy system in the following two cases.

Case 1: Hybrid wind energy system with STATCOM

Case 2: Hybrid wind energy system with constrained crow search algorithm regulated compensator

The hybrid system is created with two inputs to the solar panel being temperature and irradiation. The DC output voltage form the solar energy system is combined with the output from the wind energy system. However the wind energy system produces three phase output and hence it is first converted to DC voltage and merged with the output of the solar system. This combined output is then fed to the inverter for its DC/AC conversion.

The solar panel has been modelled with PV arrays having 10 cells connected in each series with 40 parallel branches that together give out the DC output from the system. The variable illumination of 1000 lux is provided along with varying temperature of $25^{\circ} \mathrm{C}$.This output is then merged with the DC output from the wind energy system and further sent to the inverter for its $\mathrm{AC}$ conversion. The DC output wavefrom have been illustrated in the fig. below

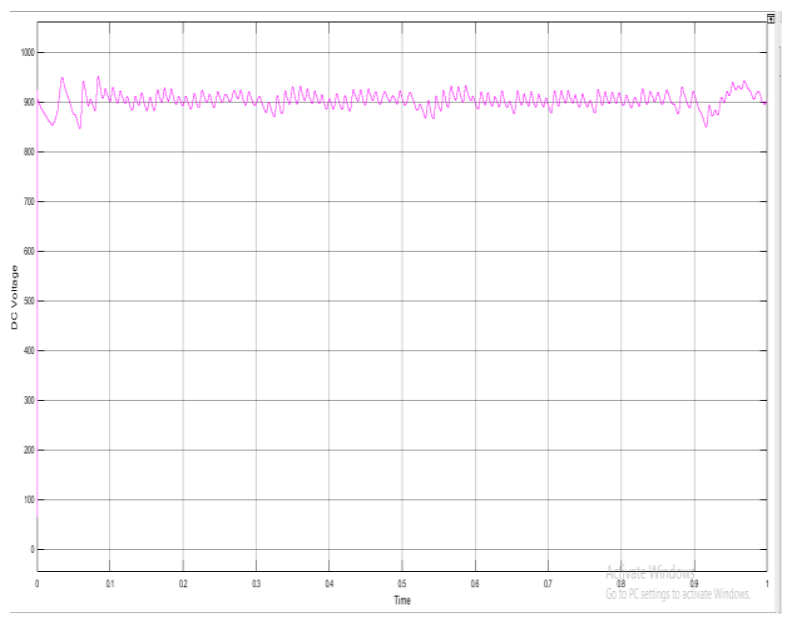

Fig. 7. DC output voltage from the hybrid energy system when STATCOM compensator is used

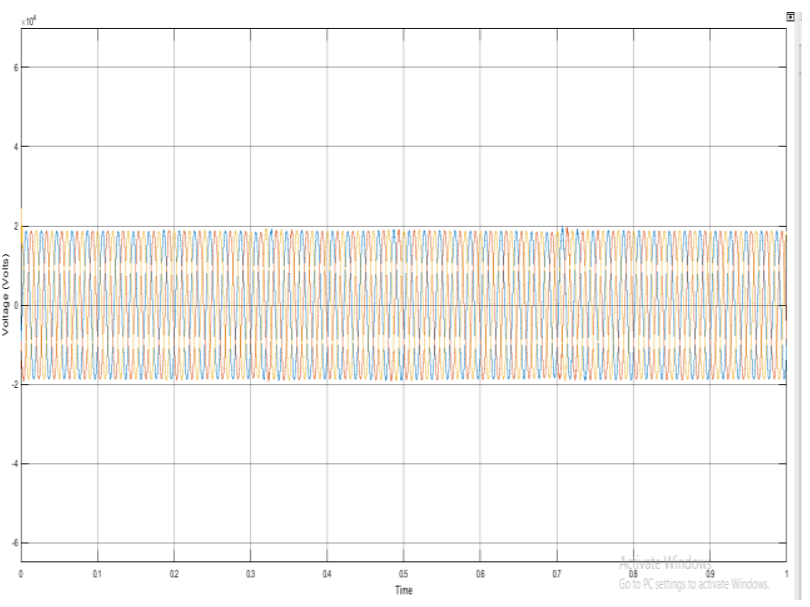

Fig. 8. Voltage output from the inverter in system having statcom at bus B1

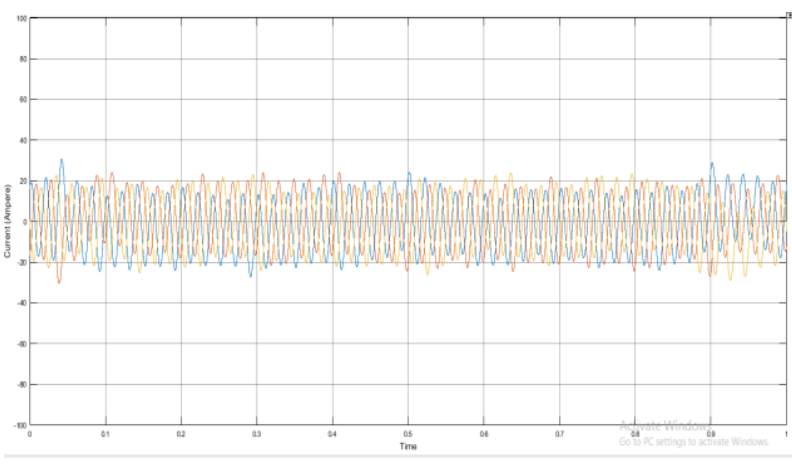

Fig. 9. Current output from the inverter in system having statcom at bus B1

Case 1: Hybrid wind energy system with STATCOM

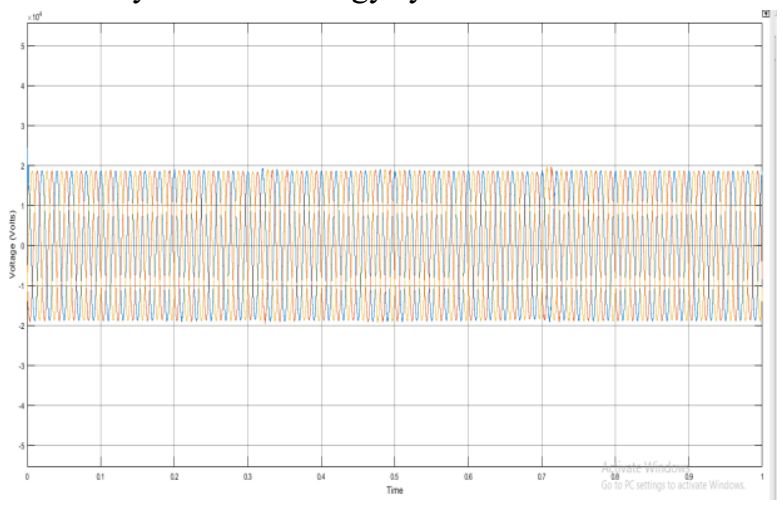

Fig. 10. Voltage output from the system with STATCOM at bus B2 (loads) 


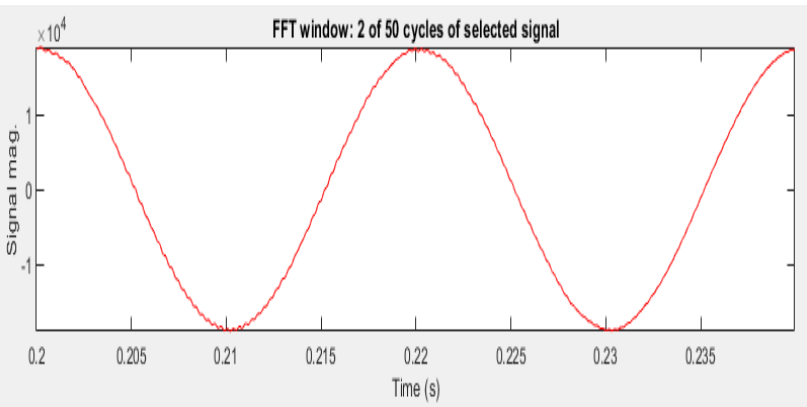

Fig. 11. FFT window of Voltage output from the inverter in system having statcom

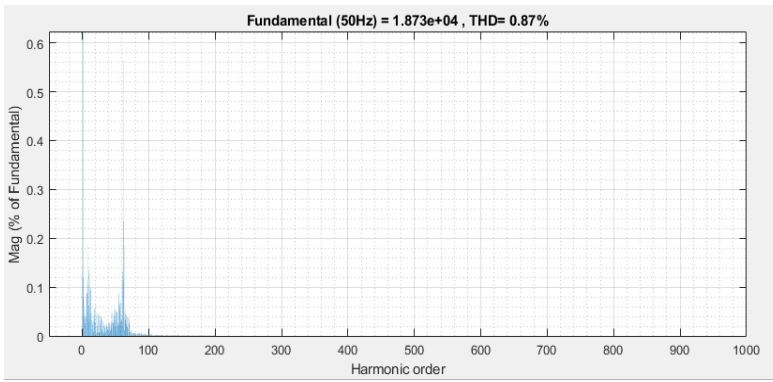

Fig. 12. THD \% Voltage output from the inverter in system having statcom

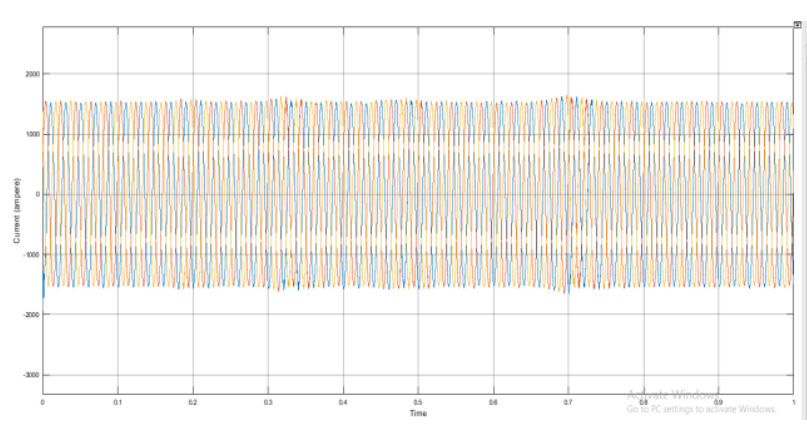

Fig. 13. Current output from the system with STATCOM B2 (loads)

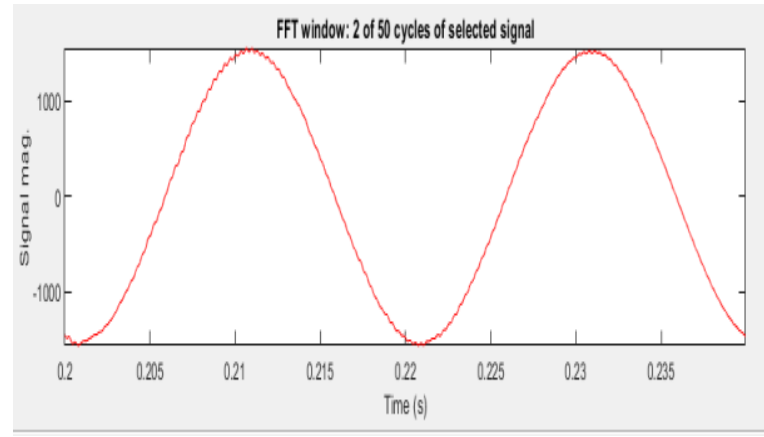

Fig. 14. FFT window of Current output from the system with STATCOM

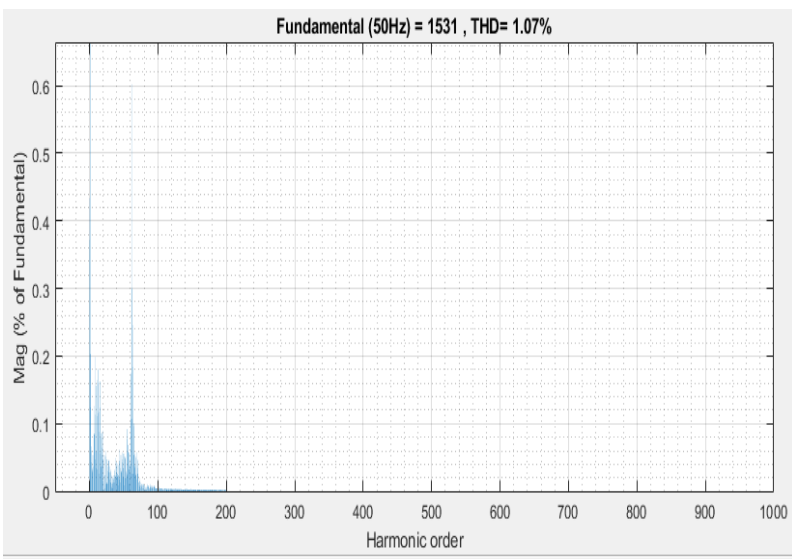

Fig. 15. THD\% of Current output from the system with STATCOM

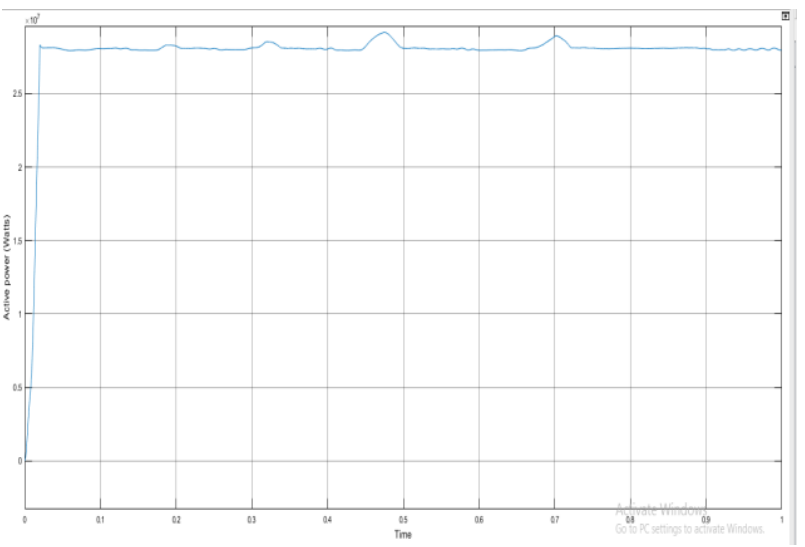

Fig. 16. Active power output from the system with STATCOM B2 (loads)

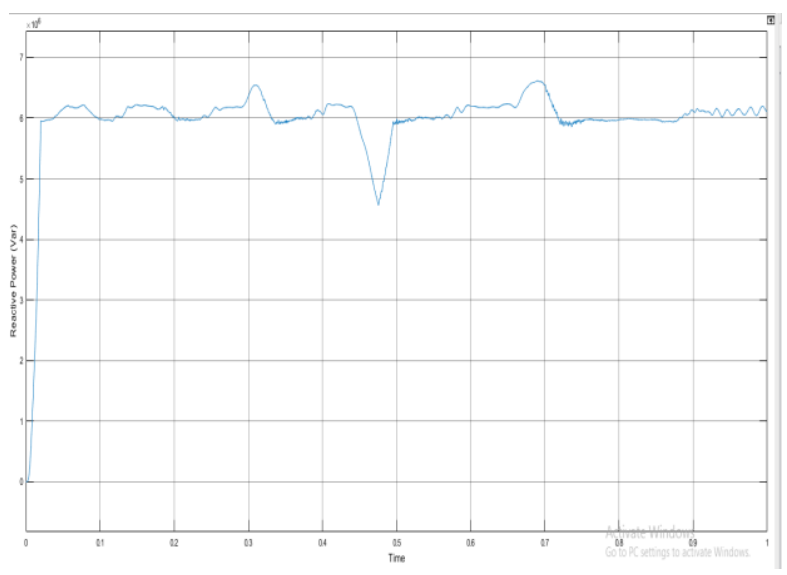

Fig. 17. Reactive power output from the system with STATCOM B2 (loads)

Case 2: Hybrid wind energy system with constrained crow search algorithm regulated compensator 


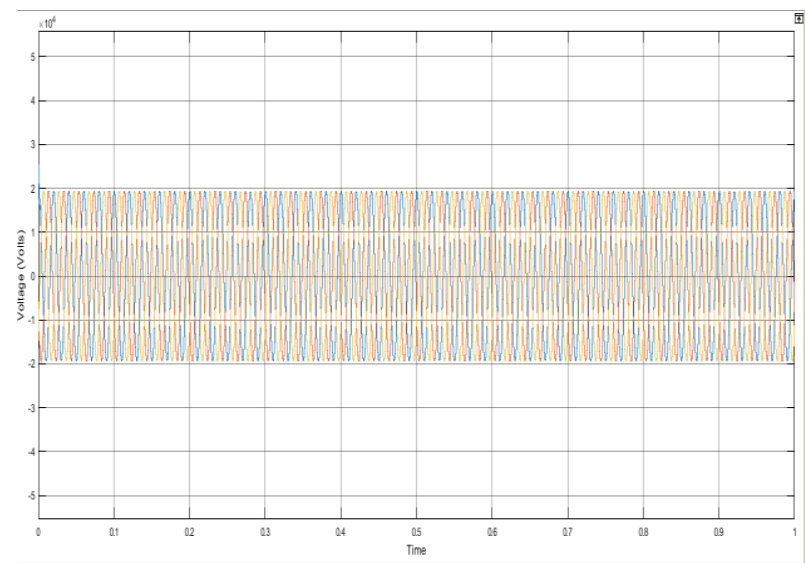

Fig. 18. Voltage output from the system with constrained crow search algorithm regulated compensator

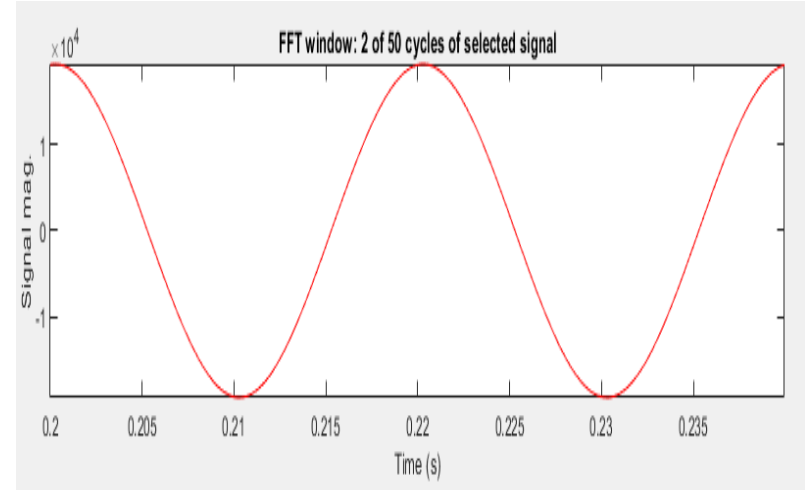

Fig. 19. FFT window of Voltage output from the system with CCSA regulated compensator

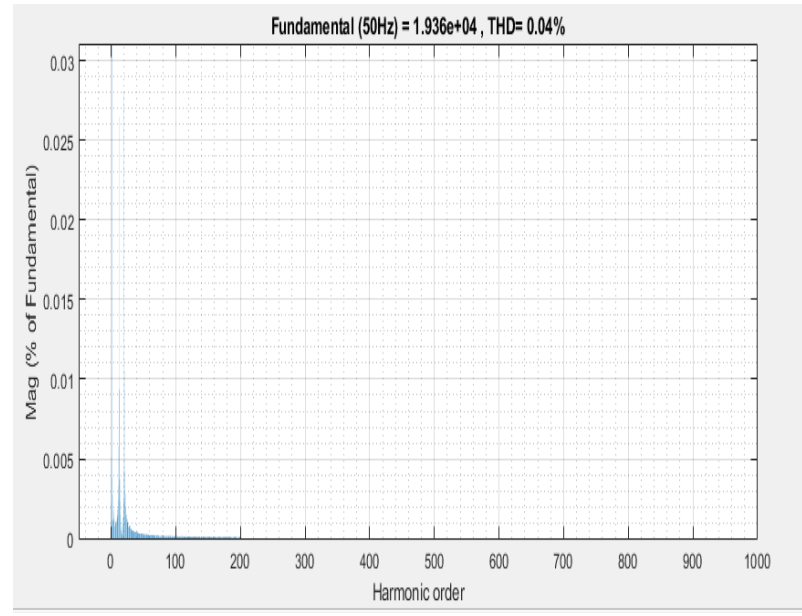

Fig. 20. THD\% of Voltage output from the system with CCSA regulated compensator

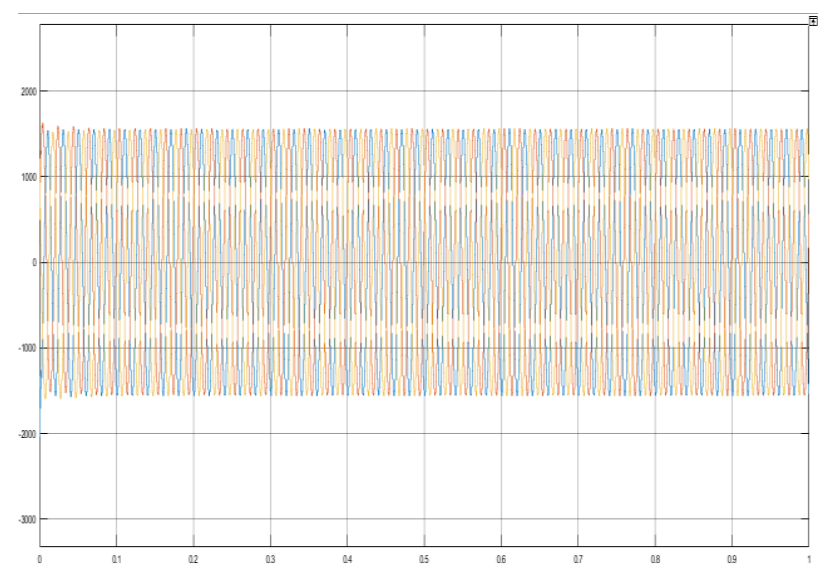

Fig. 21. Current output from the system with constrained crow search algorithm regulated compensator

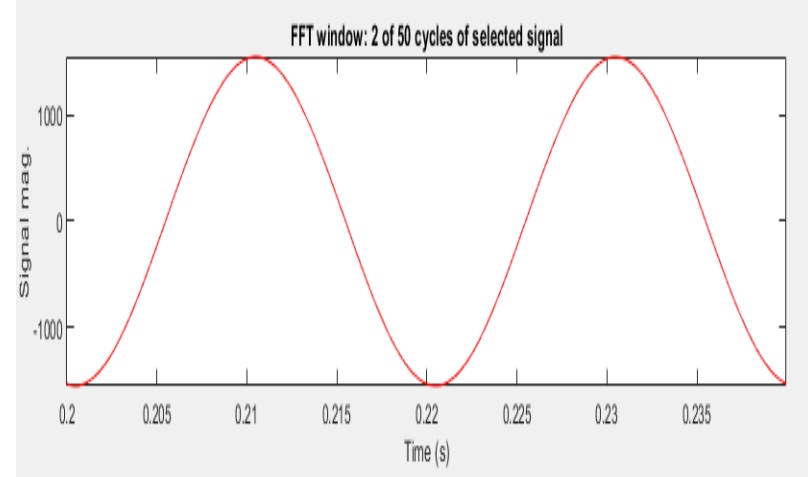

Fig. 22. FFT window of Current output from the system with CCSA regulated compensator

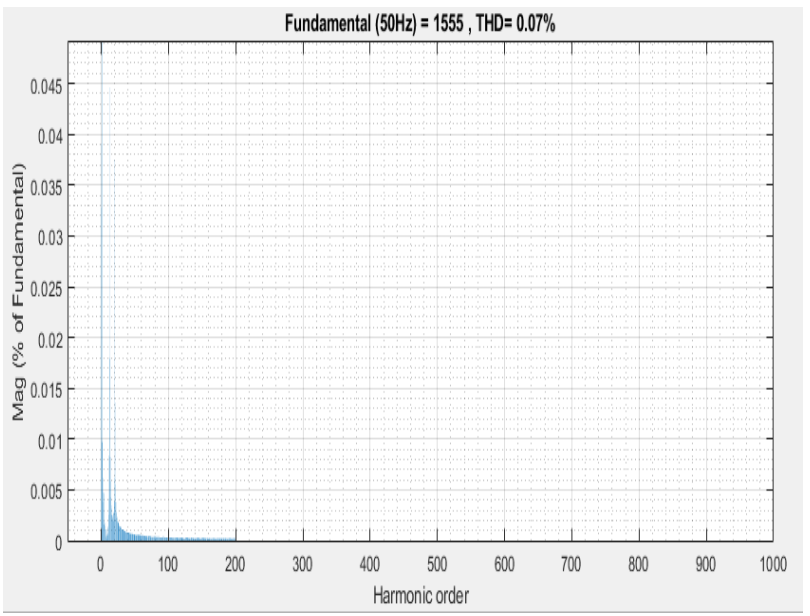

Fig. 23. THD\% of Current output from the system with CCSA regulated compensator 


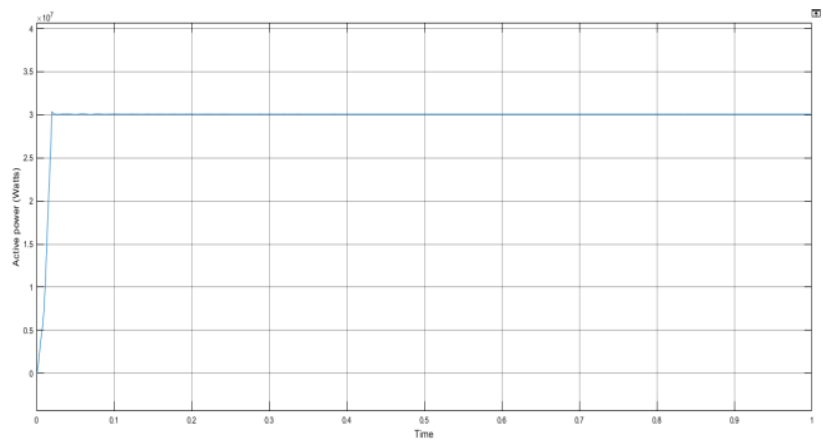

Fig. 24. Active power output from the system with constrained crow search algorithm regulated compensator

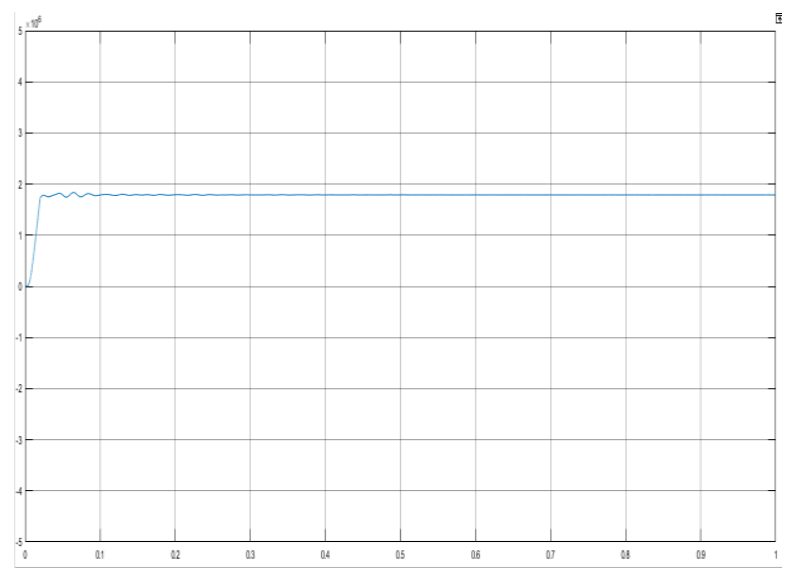

Fig. 25. Reactive power output from the system with constrained crow search algorithm regulated compensator

\section{VALIDATION}

This chapter shall discuss the comparative outcomes of the compensators. The compensator modeled with constrained crow search based algorithm is expected to produce better results as compared to the traditional STATCOM.

\begin{tabular}{|l|l|l|}
\hline & $\begin{array}{l}\text { System with } \\
\text { STATCOM }\end{array}$ & $\begin{array}{l}\text { System with CCSA } \\
\text { regulated } \\
\text { compensator }\end{array}$ \\
\hline $\begin{array}{l}\text { Active power } \\
\text { output }\end{array}$ & $28 \mathrm{MW}$ & $30 \mathrm{MW}$ \\
\hline Voltage Output & $20 \times 10^{4} \mathrm{~V}$ & $20 \times 10^{4} \mathrm{~V}$ \\
\hline Current Output & $1500 \mathrm{~A}$ & $1600 \mathrm{~A}$ \\
\hline THD\% in voltage & $0.87 \%$ & $0.04 \%$ \\
\hline THD \% in current & $1.07 \%$ & $0.07 \%$ \\
\hline $\begin{array}{l}\text { Reactive Power } \\
\text { output }\end{array}$ & $6 \mathrm{MVar}$ & $2 \mathrm{MVar}$ \\
\hline
\end{tabular}

The above results shows the comparative values of all the parameters. The active power output available has been enhanced from approximately $28 \mathrm{MW}$ at the load distribution bus in the system having STATCOM to 30
MW in the system which is made with the compensator driven by the constrained crow search algorithm (CCSA).

\section{CONCLUSION}

The demand for electricity increases day by day, which cannot be covered only by non-renewable energy sources. Renewable energy sources such as sun and wind are omnipresent and environmentally friendly. Renewable energy sources are new options for meeting energy needs, but are not reliable due to the stochastic nature of their occurrence. The hybrid renewable energy system (HRES) combines at least two renewable energy sources such as wind turbines and solar systems.

The paper here presents a hybrid system for renewable energies in a MATLAB / SIMULINK environment for analysis. We have developed a controller for the compensator based on the optimization algorithm that is part of artificial intelligence. Following main conclusions were drawn:

- The active power output from the system has enhanced to $30 \mathrm{MW}$ in the system having compensator regulated from the proposed controller that is constrained crow search algorithm from $28 \mathrm{MW}$ which is also stable as compared to the system having STATCOM.

- The Crow search algorithm is so constrained in a manner such that the output voltage and current distortion has also reduced. The voltage output distortion level from the hybrid solar wind energy system was found to be $0.04 \%$ which is less than 0.87 $\%$ of the system having basic STATCOM.

- The crow search algorithm has collectively proved to be effective reducing the distortion level of current output also. The current distortion level has also come down to $0.07 \%$ using the proposed controller from the $1.07 \%$ in the solar wind hybrid system with basic STATCOM.

- The system is also integrated with the grid energy system. The line voltage being maintained to 20 KVolts. The reactive power output has also reduced. The algorithm has proven to be more effective in the compensating the reactive power as well.

The above description concludes that the hybrid system is made efficient for driving the loads having enhanced 
active power output at its terminal. The voltage available has been made less distorted and the THD level in current output has also came down.

\section{FUTURE SCOPE}

The modulation technique is easy and simple to be implemented; use of proper facts devices can make it more robust and easy to handle inverter. With the advent of more powerful artificial intelligence, the requirements for low computational complexity and memory consumption of the algorithms will drop and it might be even possible to implement more complicated and more efficient algorithms. The proposed controller has proved be effective while designing the compensator. This algorithm can further work in an enhanced manner by making a hybrid technique for this algorithm. Therefore, it is certainly true that the area of compensator is and for a long time will remain widely opened sphere for scientific research and commercial applications.

\section{REFERENCES}

[1] Emad Jamil, Salman Hameed "Power quality improvement of distribution system with photovoltaic and permanent magnet synchronous generator based renewable energy farm using static synchronous compensator" Sustainable Energy Technologies and Assessments 35(C):98-116 - July 2019.

[2] Tariq Kamal, Luis M. Fernández-Ramírez "Dynamic Operation and Supervisory Control of a Photovoltaic/Fuel cell/Supercapacitor/Battery Hybrid Renewable Energy System" International Conference on Electrical, Communication, and Computer Engineering (ICECCE), July 2019.

[3] Gilberto Gonzalez-A, Noe Barrera-G "Dynamic performance of a Skystream wind turbine: A bond graph approach" Cogent Engineering 6(1) $\cdot$ December 2019

[4] Sujit Kumar Bhuyan, Prakash Hota "Modeling and simulation of hybrid energy system supplying $3 \varnothing$ load and its power quality analysis" International Journal of Renewable Energy Research 8(1):592-603 - January 2018.

[5] Donatella Zappala, Nur Sarma "Electrical \& Mechanical Diagnostic Indicators of Wind Turbine Induction Generator Rotor Faults" Renewable Energy 131 · June 2018.

[6] Fa Wang, Mario Garcia-Sanz "Wind farm cooperative control for optimal power generation" Wind Engineering 42(6):0309524X1878037 · June 2018.

[7] Shuai Cao, Wang Xiang "AC and DC fault ride through hybrid MMC integrating wind power" The Journal of Engineering 1(1) - November 2017.

[8] C. Xu, D. Chen "Study of integrated optimization design of wind farm in complex terrain" Taiyangneng Xuebao/Acta Energiae Solaris Sinica 38(12):3368-3375 - December 2017.

[9] Yashwant Sawle, S.C. Gupta "Review of hybrid renewable energy systems with comparative analysis of off-grid hybrid system" Renewable and Sustainable Energy Reviews · June 2017

[10] Renu Sharma, Sonali Goel "Performance evaluation of standalone, grid connected and hybrid renewable energy systems for rural application: A comparative review" Renewable and Sustainable Energy Reviews 78:1378-1389 · May 2017 